\title{
Forças e fraquezas do curso de Gestão Ambiental da Universidade de Brasília
}

\author{
Alexandre Nascimento de Almeida ${ }^{1}$
}

\section{Resumo}

Com a aplicação dos recursos do Programa de Apoio a Planos de Reestruturação e Expansão das Universidades Federais (REUNI), a Universidade de Brasília (UnB) ampliou e democratizou seu número de vagas, priorizando a criação de cursos noturnos em regiões periféricas de Brasília. Nesse contexto, criou-se o curso de Gestão Ambiental (GAM) na Faculdade UnB de Planaltina (FUP), em 2008. Em sua primeira avaliação pelo Ministério da Educação (MEC), o curso de GAM da UnB alcançou nota 4, aproximando-se da nota máxima, que é 5. Resultados de pesquisa, porém, revelaram uma alta taxa de evasão e uma baixa empregabilidade do curso, levantando dúvidas sobre sua qualidade e a efetividade da avaliação do MEC. Assim, o objetivo deste estudo foi avaliar a qualidade do curso de GAM da UnB, identificando seus pontos fortes e fracos por meio da percepção de seus egressos. Para tanto, analisaram-se 43 questionários respondidos por egressos do curso por meio da análise de cluster. 0 estudo revelou que os pontos fortes estiveram relacionados à alta qualidade dos professores, dos servidores e da infraestrutura geral da UnB. Os pontos fracos referem-se a dificuldades inerentes ao fato de o curso ser novo e ainda não reconhecido por um conselho de classe. Questões relacionadas à grade curricular do curso, à qualidade dos laboratórios e da biblioteca, bem como à inclusão dos alunos em projetos de iniciação cientifica, de extensão e em estágios na área de formação se encontraram com qualidade intermediária.

\section{Palavras-chave}

Gestão ambiental - Egressos - Avaliação institucional.

\section{Strengths and weaknesses of the Environmental Management course at the University of Brasilia}

\section{Abstract}

By utilizing the funds from the Federal University Restructuring and Expansion Plans (REUNI), the University of Brasilia (UnB) increased and democratized the number of vacancies, prioritizing the creation of night courses in the poor areas of Brasilia. In this context, the Environmental Management course (GAM) was created at the Faculdade UnB

1- Universidade de Brasília (UnB), Brasilia, DF, Brasil. Contato: alexalmeida@unb.br. 
de Planaltina (FUP) in 2008. In its first evaluation by the Ministry of Education (MEC), UnB GAM course achieved grade 4, not far from the maximum mark, which is 5. Research results, however, revealed a high dropout rate and low employability of degree holders, raising doubts about its quality as well as the effectiveness of MEC evaluation. Thus, the objective of this study was to evaluate the quality of the UnB GAM course by identifying its strengths and weaknesses through the perception of its former students. To do so, 43 questionnaires were reviewed through cluster analysis. The study revealed that the strengths were associated with the high quality of professors, workers and overall infrastructure of UnB. Weaknesses are found in difficulties inherent to the fact that the course is new and has not yet been recognized by an official professional board. Questions related to the curricular structure of the course, the quality of the laboratories and the library as well as incorporating students in projects of supervised undergraduate research, extension and internships in the respective training area were seen as showing intermediate-level quality.

\section{Keywords}

Environmental management - Former students - Institutional evaluation.

\section{Introdução}

0 gestor ambiental é um profissional capacitado para articular todas as dimensões do campo ambiental, estando dotado de capacidades de liderança, articulação e conhecimento interdisciplinar (ALMEIDA Jr., 2007). A competência do gestor não se expõe, somente, na assinatura de laudos técnicos, mas na busca de soluções para problemas ambientais complexos.

Os cursos de graduação (tecnólogo/bacharelado) da área de Gestão Ambiental (GAM) são relativamente novos. 0 primeiro curso de bacharelado em GAM foi implantado em São Paulo no ano de 2002, na Escola Superior de Agricultura Luiz de Queiroz (SCHENKEL, 2012). Até 2015, havia 3.152 cursos de GAM no Brasil, sendo que, desse total, 22 eram cursos na modalidade de bacharelado ofertados em instituições de ensino federal e 3.123 eram cursos tecnológicos ofertados em instituições públicas e privadas (BRASIL, 2015).

Os cursos de GAM estão disponíveis nos graus de tecnólogo e bacharelado. Embora o papel social desempenhado por esses profissionais possua especificidades de atuação, ambas as modalidades são, organicamente, articuladas entre si (UNB, 2011b).

0 curso de tecnólogo é uma graduação de nível superior, sendo mais aprofundado que o técnico, e engloba conteúdos específicos da área de gestão ambiental. É um curso de duração mais curta, com periodicidade entre 2 e 3 anos, e tem como objetivo formar um profissional que deseja iniciar uma carreira imediatamente (UNIVERSO EAD, s/d).

0 curso de tecnólogo ambiental é dotado de conhecimento multidisciplinar, capacitando o profissional para analisar problemas ambientais, desenvolver projetos para a recuperação de ambientes degradados e adequar tecnologias de gestão para tratamento e controle. 0 tecnólogo pode atuar no setor público ou privado e em áreas urbanas, rurais ou industriais (ANHANGUERA, s/d). Já o bacharelado em GAM forma o profissional que, 
amparado em diagnósticos de qualidade ambiental, é capaz de promover condições ideais para gerenciar a solução dos problemas ambientais, solucionar conflitos e fiscalizar o cumprimento da legislação ambiental.

0 curso de bacharelado em GAM da UnB tem como finalidade prover uma formação profissional com ampla visão interdisciplinar e sólida base científica do saber ambiental. Dessa maneira, tal profissional será capaz de desenvolver a compreensão e ter competência técnico-administrativa para atuar nas complexas inter-relações dos meios natural, social, político, econômico, cultural, ideológico e territorial (UNB, 2011b).

Ainda segundo o Projeto Político-Pedagógico do curso de Gestão Ambiental da UnB (UNB, 2011b), o curso de graduação em GAM da UnB, situado no campus de Planaltina (FUP), foi criado na perspectiva de atender à crescente demanda de formação profissional para atuar na área ambiental. Desde a sua criação até o ano de 2014, o curso já formou mais de 90 bacharéis. 0 perfil do profissional egresso do curso é interdisciplinar, de forma a estar preparado para atuar na mediação de conflitos e dilemas gerados por ações antrópicas no ambiente, bem como avaliar soluções ou medidas atenuadoras.

Para o referido curso alcançar seus objetivos e buscar uma melhoria contínua de sua qualidade, é fundamental que se tenha uma gestão educacional que incorpore uma avaliação periódica, objetiva e documentada de vários aspectos que impactam os resultados do curso. Segundo Fonseca e Fonseca (2016), a forma como a gestão institucional organiza, pedagógica e administrativamente, os cursos faz a diferença quanto à sua qualidade. Por outro lado, Saul (2015) alerta para as consequências da avaliação, sob a lógica do controle, na mercantilização da educação e na perda do seu caráter democrático e emancipatório.

A avaliação dos cursos superiores no Brasil é realizada pelo MEC e, em sua primeira avaliação, em 2013, o curso de GAM da UnB alcançou nota 4. Embora a nota tenha se aproximado da nota máxima, que é 5, em uma ampla pesquisa com egressos Neres (2015) constatou alta evasão e baixa empregabilidade para os ex-alunos do curso. Os resultados de Neres (2015) sugeriram baixa efetividade da avaliação do MEC na verificação se o curso de GAM da UnB está preparando os alunos para o mercado de trabalho. Nesse sentido, o autor propôs a ampliação dos indicadores utilizados, incorporando, inclusive, dados sobre os egressos nessa avaliação. Conforme Neres (2015, p. 14),

[...] apesar do esforço do MEC na avaliação da qualidade dos cursos de graduação, os indicadores utilizados têm sido limitados, pois não avaliam o impacto da formação superior na vida do aluno e na sociedade, elevando a importância de pesquisas de egressos com essa finalidade. A participação do egresso na avaliação da qualidade de um curso é fundamental, pois é o egresso que vivencia a realidade do mercado de trabalho e pode contribuir apontando o que em sua formação contribuiu positivamente ou negativamente em sua vida e carreira profissional.

Nessa mesma direção, Souza (2016), Cancian (2016), Espartel (2009) e Carrijo et al. (2007) ressaltaram a importância das pesquisas com egressos para a avaliação acadêmica. Tais autores afirmam que a avaliação dos cursos se torna mais efetiva quando a participação do egresso acontece e que as pesquisas de egressos se constituem numa ação importante para o planejamento, a definição e a retroalimentação das políticas educacionais das instituições. 
Nesse contexto, o presente estudo tem como objetivo avaliar a qualidade do curso de Gestão Ambiental da Faculdade UnB de Planaltina por meio da percepção dos egressos e, especificamente, apontar os pontos fortes e fracos do curso, fornecendo informações para quaisquer intervenções que busquem ampliar sua qualidade educativa.

\section{Fundamentação teórica}

\section{0 curso de Gestão Ambiental}

Os cursos de GAM são relativamente recentes na história da educação brasileira, bem como na ocupação profissional. Os registros apontam que o primeiro curso foi instituído em 1998 no modelo de curso superior de tecnologia. Somente em 2002 deu-se início às atividades acadêmicas do primeiro curso de bacharelado em GAM na Escola Superior de Agricultura Luiz de Queiroz (ESALQ) da Universidade de São Paulo (SCHENKEL, 2012).

Schenkel e Cunha (2014) retratam que a expansão da oferta dos cursos de GAM foi significativa no contexto social, político e econômico, sendo intensificada por ações dos movimentos ambientalistas a partir da década de 1970. Porter (1998) destaca que a questão ambiental não deve ser recebida como uma ameaça e sim como uma oportunidade estratégica para uma mudança de perspectiva em que os gestores enxerguem a variável ambiental.

Nesse contexto, a gestão ambiental pode ser entendida como um conjunto de diretrizes e de atividades administrativas e operacionais que integram o planejamento, a direção, o controle e a alocação de recursos, com o objetivo primordial de alcançar efeitos positivos sobre o meio ambiente, mitigando ou eliminando os impactos negativos causados pela ação humana (BARBIERI, 2011).

Leandro e Neffa (2011) caracterizam a importância da gestão ambiental como um saber constituído para a articulação de ações de diferentes agentes sociais. Nessas circunstâncias, o papel da educação superior tem sido um importante mecanismo para a formação de conhecimentos, habilidades e valores orientados para colaborar com a solução de problemas ambientais da sociedade.

Segundo a proposta político-pedagógica (PPP) do curso (UNB, 2011b), a graduação em GAM da UnB foi criada na perspectiva de se correlacionar com a crescente e duradoura demanda de formação profissional especializada e qualificada para atuar na área ambiental. 0 curso possui uma composição interdisciplinar e agrupa diversas áreas de conhecimento, cabendo ao gestor ambiental compreender ferramentas básicas de administração e economia, entre outras áreas das ciências humanas, sociais e biológicas.

Ainda de acordo com a PPP (UNB, 2011b), o referido curso é oferecido no modelo de bacharelado, ofertado no período noturno e com carga horária de 2.790 horas. A sua matriz curricular conta com 186 créditos a serem obtidos no tempo mínimo de conclusão de oito semestres letivos, sendo 132 créditos de disciplinas obrigatórias e de extensão e 54 de disciplinas optativas, de módulo livre e atividades complementares.

\section{Sistema de avaliação pedagógica do curso}

O Sistema Nacional de Avaliação da Educação Superior foi criado pela Lei $\mathrm{n}^{\circ}$ 10.861/2004 e é formado por três principais componentes: avaliação das instituições, dos 
cursos e do desempenho dos estudantes (BRASIL, 2004). Esse sistema possui uma série de instrumentos complementares, os quais são divididos em autoavaliação e avaliação por mecanismos externos. Para a realização dessa avaliação, são considerados o ensino, a pesquisa, a responsabilidade social, o desempenho dos alunos, a gestão da instituição, o corpo docente e as instalações (INEP, 2011). Conforme o Sistema Nacional de Avaliação do Ensino Superior (SINAES, 2004, p. 9),

A avaliação interna ou autoavaliação consiste em produzir conhecimentos, ou seja, pôr em questão os sentidos do conjunto de atividades e finalidades da instituição de ensino, buscando identificar as causas dos problemas e deficiências, aumentar a consciência pedagógica e capacidade profissional. Essa autoavaliação baseia-se em um processo cíclico, criativo e renovador de análise que definem a instituição.

Conforme a PPP do curso (UNB, 2011b), é prevista uma avaliação pedagógica interna, partindo-se do princípio de que essa avaliação deverá ser uma operação sistemática e contínua por meio do recolhimento de informações sobre os alunos, incluindo o desempenho, seus interesses e algumas características sociodemográficas. A avaliação é prevista para ser realizada pelo Núcleo Docente Estruturante (NDE), constituído por professores eleitos em reunião de colegiado e por representante discente. Entretanto, até o momento, o NDE do curso não tem exercido o seu papel e não realizou nenhuma avaliação do curso.

Ainda em relação à PPP (UNB, 2011b), é importante salientar os mecanismos avaliativos internos da UnB para todos os seus campi e cursos, que se caracterizam pela avaliação diagnóstica da motivação dos alunos, efetuada por meio de questionários semiestruturados direcionados para os discentes, bem como pela realização periódica de oficinas anuais envolvendo estudantes e professores para fornecer feedback dos objetivos pedagógicos e de possíveis mudanças no processo educativo da instituição.

Desde 2003, a avaliação discente é realizada na UnB, sendo o questionário aplicado em sala de aula até o primeiro semestre de 2011. A partir do segundo semestre de 2011, foram introduzidas alterações no conteúdo dos questionários e no procedimento de coleta de informações, que se tornou eletrônico e parte integrante do procedimento de matrícula (UNB, 2011a).

0 questionário direcionado aos estudantes nos cursos da UnB tem um papel significativo no processo avaliativo, contemplando a percepção dos discentes em relação à qualidade das disciplinas, do corpo docente, das aulas práticas, dos laboratórios, da biblioteca e de outras instalações. Embora a UnB possua um sistema estruturado de avaliação discente, as ações para verificar a situação do egresso ainda não são consolidadas e periódicas.

Segundo Sampaio (2013), o processo de acompanhamento da integração de egressos ao mercado de trabalho não é comum: poucas instituições ou pesquisadores realizaram avaliações nesse intuito e, igualmente, não se sabe de instituições de ensino que procuram realizar qualquer tipo de sistematização para obtenção de informações desse aluno.

Brandalise (2012) enfoca a necessidade de políticas de acompanhamento de ex-alunos para confrontar a qualidade da formação recebida, mas essa prática esbarra na falta de dados sobre os egressos, impossibilitando o retorno de informações sobre a qualidade curricular, a ética, a inserção no mercado, a satisfação profissional e a continuidade da formação. 
Ainda segundo Brandalise (2012), o feedback dos egressos em relação ao ensino ofertado pela instituição é necessário para a proposição das mudanças nos currículos, nos processos de ensino-aprendizagem e na gestão universitária para averiguar a trajetória profissional e acadêmica após a conclusão do curso, sendo uma importante referência para a avaliação da qualidade acadêmica da instituição formadora.

Meira e Kurcgant (2016) enfatizam que o egresso enfrenta, no seu cotidiano, situações complexas que o levam a confrontar as competências desenvolvidas durante o curso e que são base para o exercício profissional. Por isso, ele possui a capacidade de avaliar a adequação da estrutura pedagógica do curso, bem como os aspectos intervenientes no processo de formação acadêmica.

\section{Material e métodos}

\section{Dados}

Os dados desta pesquisa foram obtidos por meio da aplicação de questionário eletrônico para os egressos do curso de GAM da UnB. A coleta de dados ocorreu durante o período de junho a agosto de 2015 e considerou a população de alunos formados desde a criação do campus (ocorrida no primeiro semestre de 2006) até o segundo semestre de 2014, totalizando uma população de 91 egressos no período analisado.

No intuito de ampliar o tamanho da amostra, após o envio por e-mail dos questionários, foi feito contato por telefone com os ex-alunos da população amostrada, explicando os objetivos e a importância da participação na pesquisa. A obtenção do endereço de e-mail e dos contatos de telefones dos egressos ocorreu juntamente à Secretaria de Administração Acadêmica (SAA) do campus.

\section{Avaliação do tamanho da amostra}

Adotando o mesmo método de Timossi, Santos e Francisco (2008), a avaliação do tamanho da amostra ocorreu por meio do cálculo da margem de erro da amostra (E), considerando o método da estimativa da proporção populacional para população finita e admitido um grau de confiança de 95\% $(1,96)$ no seu cálculo (equação 1).

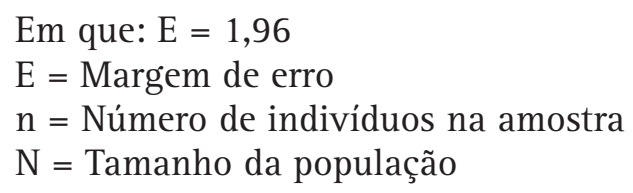

A opção por esse método se deve ao fato de os dados serem coletados em escala ordinal, não permitindo cálculos de média e desvio padrão, bem como ao fato de a população não ser demasiadamente grande, podendo ser considerada como finita (MARTINS, 2006). As pesquisas com egressos de Neres (2015), Souza (2016) e Cancian (2016) avaliaram suas amostras pelo mesmo método. 


\section{Questionário}

0 questionário contou com afirmativas relacionadas à qualidade do curso de GAM da UnB, sendo mensurada a opinião dos egressos por meio da escala de Likert (1932). Para tanto, foram apresentadas afirmações relacionadas à qualidade do curso aos entrevistados para que eles indicassem seu grau de concordância entre cinco atributos: discorda completamente (DC); discorda (D); indiferente (I); concorda (C) e concorda completamente (CC). 0 maior grau de concordância para cada afırmativa indicou uma melhor situação da variável no que tange à qualidade do curso.

0 conteúdo das afirmativas envolveu aspectos inerentes ao trabalho dos professores, à qualidade e à pertinência das disciplinas, à adequação da infraestrutura e às características inerentes ao curso (Quadro 1). As referências para a elaboração do questionário foram: o questionário de avaliação de disciplinas pelo discente da UnB (UNB, 2015); a pesquisa de Brandalise (2012) sobre a avaliação dos cursos de graduação na perspectiva dos egressos; e o relatório final de acompanhamento da carreira profissional dos ex-alunos da Universidade Federal de São Carlos (UFSCar, 2014).

\section{Quadro 1 - Afirmações presentes no questionário}

\begin{tabular}{|c|c|}
\hline Afirmações & Sigla* \\
\hline 1. Quase todos os professores possuem domínio do conhecimento sobre as disciplinas que ministram. & Cprof \\
\hline 2. Quase todos os professores possuem uma boa qualidade na transmissão do conteúdo. & Dprof \\
\hline $\begin{array}{l}\text { 3. Quase todos os professores foram comprometidos com a boa formação dos alunos (cumpriram o horário das aulas, estiveram } \\
\text { disponíveis para atendimento extraclasse e raramente faltaram). }\end{array}$ & Coprof \\
\hline 4. Quase todos os professores foram proativos na inclusão dos alunos em programas de iniciação científica. & ICprof \\
\hline 5. Quase todos os professores foram proativos na inclusão dos alunos em projetos de extensão. & EXprof \\
\hline 6. A coordenação do curso prestou bons serviços de apoio e orientação. & Coo \\
\hline 7. Quase todas as disciplinas presentes na grade curricular, obrigatórias e optativas, atendem às necessidades do curso. & Idisc \\
\hline 8. Quase todas as disciplinas apresentaram uma integração entre teoria e aspectos da realidade profissional do curso. & Adisc \\
\hline 9. A maior parte do conteúdo aprendido nas disciplinas é importante para exercer a profissão do curso em que se formou. & Cdisc \\
\hline 10. Os laboratórios possuíam equipamentos e materiais em quantidade e qualidade adequadas. & Alab \\
\hline 11. A infraestrutura da FUP em relação a sala de aula, auditório, banheiro, lanchonete e xerox foi adequada para a realização do curso. & Infra \\
\hline $\begin{array}{l}\text { 12. A secretaria de graduação prestou bons serviços de apoio aos alunos, tais como emissão de documentos, orientações e } \\
\text { informações acadêmicas. }\end{array}$ & S \\
\hline $\begin{array}{l}\text { 13. Quanto à satisfação com } 0 \text { acesso ao campus da FUP, este é bem localizado, dentro de sua área de influência e de fácil } \\
\text { acessibilidade. }\end{array}$ & Acam \\
\hline 14. A biblioteca da FUP dispunha de acervo atualizado para estudo e pesquisa na área do curso. & $\mathrm{B}$ \\
\hline 15. Aulas práticas foram em quantidade e qualidade adequadas para a formação. & Aprat \\
\hline $\begin{array}{l}\text { 16. Atividades complementares realizadas na FUP (como seminários e semana acadêmica, entre outras) foram em quantidade e } \\
\text { qualidade adequadas para a formação. }\end{array}$ & Acomp \\
\hline 17. A disponibilidade de estágios na área de formação durante a graduação foi adequada. & Dest \\
\hline 18. Não existem dificuldades inerentes ao fato de o curso ser relativamente novo e ainda pouco reconhecido pelo mercado. & Den \\
\hline $\begin{array}{l}\text { 19. Não existem dificuldades inerentes ao fato de o curso não ser reconhecido por algum conselho de classe (exemplo: CREA, OAB, } \\
\text { CRM), ou, no caso das licenciaturas, de o curso não estar regulamentado pelo MEC. }\end{array}$ & $\mathrm{Dr}$ \\
\hline
\end{tabular}

Fonte: Autoria própria.

*A correspondência exata de cada sigla está apresentada no Quadro 2. 


\section{Análise de cluster}

0 método empregado para avaliar os dados foi a análise de cluster (AC), utilizando o software SPSS ${ }^{\circledast}$ (Pacote Estatístico para Ciências Sociais) versão 22. A AC é uma técnica multivariada que serve para detectar grupos homogêneos de variáveis por meio de medidas de similaridade, como a distância euclidiana, medida de similaridade mais comum entre dois objetos (HAIR Jr. et al., 2005).

Utilizou-se a análise de cluster para verificar o agrupamento das variáveis relacionadas à qualidade do curso de GAM da UnB com os atributos definidos pela escala de Likert (1932), permitindo um exame exploratório sobre os pontos fortes e fracos do referido curso.

A formação dos grupos na análise empregada considerou o algoritmo hierárquico pelo método Ward, em que são reunidas variáveis em grupos cada vez maiores, segundo o aumento da dissimilaridade (distância euclidiana) entre eles, resultando em um dendograma.

Da mesma forma que Almeida (2010), optou-se pelo procedimento de Ward por sua tendência de combinar agrupamentos com um pequeno número de variáveis e de produzir agregados com aproximadamente o mesmo número de observações, o que facilita sua interpretação.

Após a obtenção do dendograma, buscou-se diferenciar três grupos de variáveis, conforme sua contribuição para a qualidade do curso de GAM da UnB:

- grupo com os pontos fortes do curso: variáveis que tenderam a se agrupar em torno dos atributos com alto grau de concordância;

- grupo com os pontos fracos do curso: variáveis propensas ao relacionamento junto dos atributos com baixo grau de concordância;

- meio termo: variáveis agrupadas em torno da posição de indiferença (I) ou próximas a ela.

\section{Resultados e discussões}

\section{Avaliação do tamanho da amostra}

A amostra alcançada foi de 43 questionários respondidos, representando $47 \%$ da população pesquisada. A representatividade da amostra esteve acima do encontrado na literatura, por exemplo, nos trabalhos de Brandalise (2012) e de Sampaio (2013), com amostras de $20 \%$ e $16 \%$ das respectivas populações.

A margem de erro calculada foi de 11\%, inferior ao valor de 15\% que Neres (2015) aceitou em sua pesquisa e superior ao erro amostral aproximado de $8 \%$ das pesquisas de Souza (2016) e Cancian (2016). Assim como Almeida (2010), considerou-se que a margem de erro calculada não foi elevada a ponto de justificar a necessidade de ampliação da amostra, admitindo-a como representativa da população de egressos analisada. 


\section{Pontos fortes e fracos do curso de GAM da FUP}

A análise de cluster permitiu diferenciar os pontos fortes e fracos das variáveis situadas no meio termo, com uma distância euclidiana de três unidades (figura 1). 0 resumo dos resultados é apresentado no Quadro 2.

Figura 1 - Resultados da análise de cluster

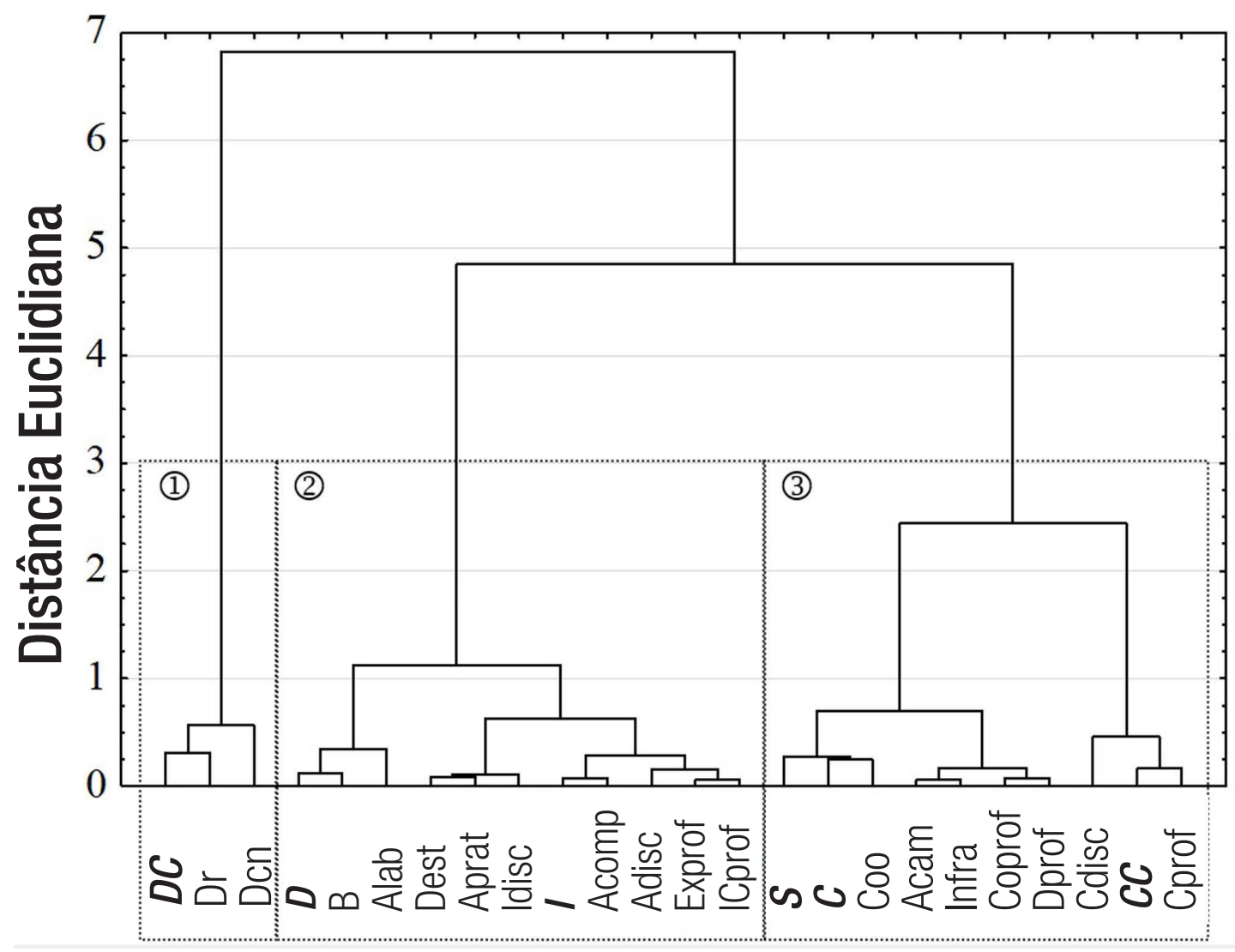

Legenda: (1) Pontos francos; (2) Meio termo; (3) Pontos fortes Fonte: Autoria própria.

Os resultados indicaram que os pontos fracos do curso de GAM da UnB estiveram relacionados à novidade do curso (Dcn) e ao seu não reconhecimento por algum conselho de classe (Dr), como o CREA, a OAB ou o CRM, sugerindo ações prioritárias pela UnB e pelo MEC nesses dois aspectos.

Os cursos de GAM são relativamente recentes na história da formação profissional de ensino superior. Sua expansão fez-se num contexto controverso, pois, primeiramente, 
Quadro 2 - Interpretação dos resultados da análise de cluster

\begin{tabular}{|c|c|c|c|c|c|}
\hline \multicolumn{2}{|r|}{ Pontos fortes } & \multicolumn{2}{|r|}{ Meio termo } & \multicolumn{2}{|r|}{ Pontos fracos } \\
\hline Cprof & Conhecimento dos professores & Acomp & $\begin{array}{l}\text { Adequação das atividades } \\
\text { complementares }\end{array}$ & \multirow{4}{*}{$\mathrm{Dr}$} & \multirow{4}{*}{$\begin{array}{l}\text { Dificuldades inerentes ao } \\
\text { fato de o curso não ser } \\
\text { reconhecido por conselho } \\
\text { de classe }\end{array}$} \\
\hline Cdisc & Conteúdo das disciplinas & Adisc & Adequação das disciplinas ao curso & & \\
\hline Coprof & $\begin{array}{l}\text { Comprometimento dos } \\
\text { professores }\end{array}$ & EXprof & $\begin{array}{l}\text { Inclusão de alunos pelos professores em } \\
\text { projetos de extensão }\end{array}$ & & \\
\hline Dprof & Didática dos professores & ICprof & $\begin{array}{l}\text { Inclusão de alunos pelos professores em } \\
\text { projetos de iniciação científica }\end{array}$ & & \\
\hline Acam & Acesso ao campus & Idisc & Importância das disciplinas & \multirow{5}{*}{ Dcn } & \multirow{5}{*}{$\begin{array}{l}\text { Dificuldades inerentes ao } \\
\text { fato de o curso ser novo }\end{array}$} \\
\hline Infra & $\begin{array}{l}\text { Qualidade da infraestrutura da } \\
\text { FUP }\end{array}$ & Aprat & Adequação das aulas práticas & & \\
\hline Coo & Qualidade da coordenação & Dest & Disponibilidade de estágios & & \\
\hline \multirow{2}{*}{ S } & \multirow{2}{*}{ Qualidade da Secretaria } & B & Qualidade da biblioteca & & \\
\hline & & Alab & Adequação dos laboratórios & & \\
\hline
\end{tabular}

Fonte: Autoria própria.

há uma falta de compreensão minimamente partilhada entre os atores sociais sobre a defınição de desenvolvimento sustentável e de sustentabilidade. Nesse sentido, surgiram compreensões conflituosas acerca da formação e do exercício profissional do gestor ambiental, resultando na falta de identidade e de perfil profissional (SCHENKEL, 2012).

Schenkel (2012) destaca, ainda, que a falta de reconhecimento está relacionada ao fato de o curso de bacharelado ainda não possuir diretrizes curriculares nacionais. Tais diretrizes são flexíveis e remetidas à responsabilidade, ao planejamento, à organização e à oferta de cursos de graduação (bacharelado) em instituições de ensino superior.

Em contexto similar ao do curso de GAM da UnB, a Proposta Pedagógica do curso de Gestão Ambiental da Universidade do Estado do Rio Grande do Norte (UERN, 2012) destaca a importância das diretrizes curriculares nacionais como um indicativo para a elaboração de currículos, devendo ser respeitadas por todas as instituições de ensino superior a fim de assegurar a flexibilidade e a qualidade de formação oferecida aos estudantes; sem as diretrizes, o processo de criação e formulação do curso é estabelecido pela Proposta Político-Pedagógica (PPP) de cada instituição, resultando numa matriz curricular diversa entre os cursos.

0 reconhecimento profissional, a regulamentação da profissão e a efetiva inserção do gestor ambiental no mercado de trabalho vêm sendo temas de debate em fóruns do Brasil, inclusive na elaboração do Projeto de Lei $n^{\circ} 2.664 / 2011$, que regulamenta o exercício da profissão do gestor ambiental (BRASIL, 2011).

0 referido projeto de lei define as atividades profissionais do gestor ambiental, bem como explicita a responsabilidade e a autoria de planos e projetos no âmbito da gestão ambiental (BRASIL, 2011). 0 projeto já obteve parecer favorável, com pequenas alterações, pelas Comissões de Educação, Meio Ambiente e Desenvolvimento Sustentável e se encontra em tramitação nas Comissões do Trabalho, da Administração e do Serviço Público e na Comissão de Constituição, Justiça e Cidadania da Câmara dos Deputados. 
Uma conquista importante para a gestão ambiental, mesmo no âmbito de cursos de tecnologia, é a aprovação do registro no CREA de diversos Estados da federação. No Distrito Federal, tecnólogos em gestão ambiental podem solicitar o registro no CREA-DF. Essa decisão beneficia milhares de gestores ambientais e garante o exercício legal da profissão, auxiliando no processo de regulamentação das áreas no Distrito Federal, que se destaca nas questões referentes ao licenciamento ambiental (GUEDES, 2015).

Espera-se que, à medida que os egressos em cursos de tecnólogo ganhem ascensão e reconhecimento profissional, os bacharelados também consigam partilhar de conquistas semelhantes, como a elaboração de diretrizes curriculares e o reconhecimento da classe.

Um conjunto de variáveis situou-se em uma posição de meio termo e, após as dificuldades inerentes ao reconhecimento (Dr) e a novidade do curso (Dcn), são as que mais demandam melhorias com vistas a aumentar a qualidade do curso de GAM da UnB. Entre as variáveis situadas no meio termo, destacaram-se a baixa qualidade da biblioteca (B) e a falta de adequação dos laboratórios às necessidades do curso (Alab).

A biblioteca no campus da FUP, inicialmente, funcionava em uma pequena sala, com livros doados pela Biblioteca Central (BCE) da UnB em caráter provisório. Somente após seis anos da inauguração do campus, em 17 de março de 2011, foi inaugurado um novo prédio que passou a abrigar a biblioteca (UnB/BCE, s/d).

Além da demora de inauguração do novo prédio para a biblioteca da FUP, a percepção negativa dos alunos pode estar relacionada ao pequeno acervo e à falta de exemplares de livros que são utilizados como literatura básica de algumas disciplinas, fazendo com que os discentes sejam obrigados a recorrer a fotocópias para estudar. Em outros momentos, os alunos precisam buscar material na BCE ou em outras bibliotecas setoriais, estas muito distantes do campus de origem do aluno da FUP.

A importância da biblioteca na formação superior foi ressaltada por Marques (2015). Para Santos (2012), a biblioteca universitária deve estar preparada para atender à demanda de pesquisas e levantamentos bibliográficos e técnicos, visando suprir os projetos em desenvolvimento na universidade. A biblioteca deve estar conectada às novas tecnologias, sendo responsável pela integração entre usuários e fontes de informação, reforçando o desenvolvimento dos cidadãos.

Em relação à falta de adequação dos laboratórios (Alab), a explicação para a percepção mediana dos egressos decorre da ausência de equipamentos modernos utilizados para a realização de análises de solo, gases e água. Outro problema é a quantidade insuficiente de equipamentos, sendo necessário que os alunos se juntem em grupos ou esperem que o equipamento seja desocupado, o que atrapalha a dinâmica das aulas.

Sato (2011) destaca que as aulas práticas e experimentais são importantes para contribuir de forma mais efetiva na formação do aluno e que, na ausência do laboratório, os alunos podem ter o conceito errado e a relação entre a teoria e a prática pode ser comprometida. Para que isso não ocorra na FUP, uma saída seria a compra de novos equipamentos ou a diminuição de alunos por turma, principalmente em disciplinas que demandam utilização frequente dos laboratórios. Além disso, é necessário uma maior agilidade na burocracia da universidade para a instalação de equipamentos já comprados, em locais já construídos e definidos. 
Três variáveis situadas no meio termo e que são importantes para a preparação dos estudantes para o mercado de trabalho estiveram relacionadas à proatividade dos professores na inclusão dos discentes em projetos de iniciação científica e extensão (ICprof e EXprof), bem como à inclusão dos estudantes em estágios na área de formação do curso (Dest) e à adequação das atividades complementares do curso (Acomp).

Lima (2015) observa que as vagas de estágio são poucas e mal divulgadas para os estudantes de GAM da UnB. Além do número reduzido de oportunidades, quando há estágio, na sua grande maioria, as vagas são para órgãos ou empresas públicas não relacionadas diretamente com as competências de gestor ambiental, implicando desvio de função e sendo pouco efetivas.

Os projetos de iniciação científica costumam demandar uma atenção maior por parte dos docentes, resultando em uma maior participação dos estudantes em comparação aos estágios na área de formação. Entretanto, os projetos de iniciação científica do curso, dado o caráter multidisciplinar dos professores, atendem mais ao anseio docente no desenvolvimento científico de suas diferentes áreas de atuação (biologia, geologia, economia, administração, sociologia, engenharia, entre outras), ficando para segundo plano a resolução de problemas exclusivos da GAM (LIMA, 2015).

Ainda em relação às variáveis situadas no meio termo, destacaram-se aquelas relacionadas com a estrutura curricular do curso, representadas pela adequação e pela importância das disciplinas (Adisc e Idisc), bem como à quantidade e à qualidade das aulas práticas (Aprat).

0 curso de GAM da UnB tem por finalidade promover uma formação profissional com ampla visão interdisciplinar, congregando diversas disciplinas nas áreas de ciências sociais e ambientais. A percepção mediana quanto à adequação e à importância das disciplinas pode ser explicada por uma falta de aplicabilidade das matérias na gestão ambiental, o que leva a uma baixa relação (sinergia) entre as disciplinas e, consequentemente, a uma interdisciplinaridade pouco efetiva do curso.

Especificamente em relação à inadequação das aulas práticas (Aprat), deve ser ressaltado o fato de o curso ocorrer predominantemente no período noturno, limitando a quantidade e a qualidade das aulas. Algumas disciplinas práticas são ofertadas aos sábados, pela manhã, o que permite sua realização, mesmo que de modo superficial. Outras disciplinas oferecem saídas de campo ou inversão do horário da aula para que se consiga promover a formação prática proposta pelo curso, porém, a baixa disponibilidade de horários, especialmente em horário comercial, limita a realização de atividades práticas e de visitas técnicas.

As variáveis que se encontraram em melhor situação estiveram relacionadas à qualidade dos professores (Cprof, Coprof, Dprof e Cdisc), à infraestrutura geral (salas de aula, auditórios, banheiros, lanchonete e xerox) (Infra) e aos serviços prestados pelos servidores administrativos da FUP para o aluno (Coo e S). Outra questão apontada pelos egressos como positiva foi o acesso ao campus da FUP (Acam).

A FUP está localizada bem próximo à entrada de Planaltina, e há placas que sinalizam o caminho para quem deseja ir até o campus. Em relação aos professores, o corpo docente é constituído, integralmente, por doutores e pós-doutores com dedicação exclusiva e contratados por concurso, o que contribui para a percepção positiva dos egressos. 


\section{Conclusões}

Os pontos fortes do curso de GAM da UnB estiveram relacionados com a alta qualidade dos professores, dos servidores e da infraestrutura da FUP. A qualidade dos recursos humanos nas universidades federais se deve à atratividade do serviço público, que ainda remunera melhor quando comparado ao setor privado e possibilita maiores segurança e flexibilidade no trabalho. Tudo isso contribui para atrair excelentes profissionais para tais instituições. Em relação à infraestrutura, a FUP foi inaugurada em 2006 e possui edifícios conservados e adequados à necessidade do campus.

Os pontos fracos referem-se a dificuldades decorrentes do fato de o curso ser novo e ainda não reconhecido por um conselho de classe. Essas questões dificultam a inclusão e a valorização do egresso da FUP no mercado de trabalho, já que, muitas vezes, não se diferenciam do profissional em gestão ambiental de nível técnico. A consolidação de qualquer curso novo demanda tempo, porém, ações da UnB e do MEC voltadas para o reconhecimento dos cursos de graduação em Gestão Ambiental, bem como para sua admissão em algum conselho de classe, podem contribuir para o fortalecimento do curso.

Questões referentes à grade curricular do curso, à qualidade dos laboratórios e da biblioteca, à inclusão dos alunos em projetos de iniciação científica, extensão e estágios na área de formação se encontraram em uma posição de meio termo e precisam ser melhoradas. Os edifícios destinados à biblioteca e aos laboratórios são novos e adequados, mas ainda não possuem o material bibliográfico e os equipamentos necessários, o que afeta, inclusive, o desenvolvimento de atividades de extensão e iniciação científıca no campus. Já a dificuldade de inserção dos estudantes em estágios na área pode ser parcialmente explicada pelo pouco reconhecimento do curso e pela reduzida atividade industrial no Distrito Federal.

\section{Referências}

ALMEIDA, Alexandre Nascimento de. Comparação entre a competitividade do Brasil e Canadá para produção de madeira serrada. 2010. Curitiba, 209 f. Tese (Doutorado em Ciências Florestais) - Universidade Federal do Paraná, 2010.

ALMEIDA Jr., Antônio Ribeiro de. Gestor ambiental: profissional ou intelectual? OLAM Ciência e Tecnologia, Rio Claro, v. 7, n. 3, p. 54-64, 2007.

ANHANGUERA. Apresentação do curso superior em tecnologia em gestão ambiental. s/d. Disponível em: $<$ http://anhanguera.com/graduacao/cursos/>. Acesso em: 2 abr. 2016.

BARBIERI, José Carlos. Gestão ambiental empresarial: conceitos, modelos e instrumentos. 3. ed. São Paulo: Saraiva, 2011.

BRANDALISE, Mary Ângela T. Avaliação dos cursos de graduação na perspectiva dos egressos: um indicador de avaliação institucional. In: ANPEDE SUL, 10., 2012, Ponta Grossa. Anais... Ponta Grossa: ANPEDE, 2012. p. $84-101$. 
BRASIL. Lei n 10.861, de 14 de abril de 2004. Institui o Sistema Nacional de Avaliação da Educação Superior - SINAES e dá outras providências. Diário Oficial da União, Brasilia, DF, 15 abr. 2004. Disponível em: <http:// www.planalto.gov.br/ccivil_03/_ato2004-2006/2004/lei//10.861.htm>. Acesso em: 13 jun. 2016.

BRASIL. Projeto de Lei $n^{0}$ 2664/2011, de 09 de novembro de 2011. Projeto que regulamenta a profissão do gestor ambiental. Brasilia, DF: [s. n.], 2011. Disponível em: <http://www.camara.gov.br/>. Acesso em: 20 maio 2016.

BRASIL. Ministério da Educação e Cultura. Sistema E-MEC: relação dos cursos de gestão ambiental. Brasília, DF, 2015.

CANCIAN, Rosânia Araújo S. Perfil e empregabilidade dos egressos dos campi agropecuários de Colorado do Oeste e Ariquemes do Instituto Federal de Educação, Ciência e Tecnologia de Rondônia. 2016. 71 f. Dissertação (Mestrado em Políticas Públicas) - Universidade de Brasília, Brasília, DF, 2016.

CARRIJO, Clarissa Irineu de S. et al. A empregabilidade de egressos de um curso de graduação em enfermagem. Revista Enfermagem UERJ, Rio de Janeiro, v. 15, n. 3, p. 356-363, 2007.

ESPARTEL, Lélis Balestrin. 0 uso da opinião dos egressos como ferramentas de avaliação de cursos: 0 caso de uma instituição de ensino superior catarinense. Revista Alcance, Biguaçu, v. 16, n. 1, p. 102-114, 2009.

FONSECA, Marília; FONSECA, Dirce Mendes. A gestão acadêmica da pós-graduação lato sensu: o papel do coordenador para a qualidade dos cursos. Educação e Pesquisa, São Paulo, v. 42, n. 1, p. 151-164, 2016.

GUEDES, Giselle. Tecnólogos em gestão ambiental podem solicitar registro no CREA - DF. Notícias CREA DF (Conselho Regional de Engenharia e Agronomia), Brasília, DF: CREA-DF, 2015.

HAIR Jr., Joseph F. et al. Análise multivariada de dados. 5. ed. Porto Alegre: Bookman, 2005.

INEP. Instituto Nacional de Pesquisas Educacionais Anísio Teixeira. Sinaes, 2011. Disponível em: <http:// portal.inep.gov.br/superior-sinaes>. Acesso em: 31 maio 2016.

LEANDRO, Luiz; NEFFA, Elza. A formação do gestor ambiental no Brasil: considerações sobre estratégia e sustentabilidade. In: SEMINÁRIO NACIONAL DA PÓS-GRADUAÇÃO EM CIÊNCIAS SOCIAIS UFES, 1., 2011, Vitória. Anais... Vitória: UFES, 2011. p. 74 - 88.

LIKERT, Rensis. A technique for the measurement of attitudes. Archives of Psychology, Chicago, v. 22, n. 140, p. 1-55, 1932.

LIMA, Maharishe de Souza. Determinantes da situação do egresso de gestão ambiental da faculdade UnB de Planaltina. 2015. 12 f. Trabalho de Conclusão de Curso (Bacharelado em Gestão Ambiental) - Universidade de Brasília, Brasília, DF, 2015.

MARQUES, Lussara Ribeiro V. Avaliação e proposta de indicadores: a contribuição do ENADE na gestão das bibliotecas universitárias. 2015. 54 f. Dissertação (Mestrado em Políticas Públicas) - Universidade de Brasília, Brasília, DF, 2015. 
MARTINS, Gilberto de Andrade. Estatística geral e aplicada. 3. ed. São Paulo: Atlas, 2006.

MEIRA, Maria Dyrce D.; KURCGANT, Paulina. Educação em enfermagem: avaliação da formação por egressos, empregadores e docentes. Revista Brasileira de Enfermagem, Brasília, DF, v. 69, n. 1, p. 16-22, 2016.

NERES, Ivonaldo Vieira. Comparação do perfil e da situação entre 0 aluno evadido e o egresso da Faculdade UnB de Planaltina - FUP. 2015. 93 f. Dissertação (Mestrado em Políticas Públicas) - Universidade de Brasília, Brasília, DF, 2015.

PORTER, Michael E. On competition. Boston: Harvard Business School, 1998. (The Harvard Business Review Book Series).

SAMPAIO, Marcus Vinicius D. Educação profissional: a expansão recente do IFRN e a absorção local dos egressos no mercado de trabalho. 2013. 183 f. Dissertação (Mestrado em Economia) - Universidade Federal do Rio Grande do Norte, Natal, 2013.

SANTOS, Marivaldina Bulcão. Biblioteca: acesso à informação e ao conhecimento. In: SEMINÁRIO NACIONAL DE BIBLIOTECAS UNIVERSITÁRIAS, 17., 2012, Gramado. Anais... Porto Alegre: UFRGS, 2012. p. 1 - 18.

SAT0, Matheus de Souza. A aula de laboratório no ensino superior de química. 2011. 116 f. Dissertação (Mestrado em Ciências-Físico-Química) - Instituto de Química de São Carlos da Universidade de São Paulo, São Carlos, 2011.

SAUL, Ana Maria. Na contramão da lógica do controle em contextos de avaliação: por uma educação democrática e emancipatória. Educação e Pesquisa, São Paulo, v. 41, n. especial, p. 1299-1311, 2015.

SCHENKEL, Cladecir Alberto. Gestão ambiental: perfil profissional e formação em cursos superiores de tecnologia e de bacharelado. 2012. 348 f. Tese (Doutorado em Educação) - Universidade Federal de Uberlândia, Uberlândia, 2012.

SCHENKEL, Cladecir Alberto; CUNHA, Ana Maria de 0. Do multidisciplinar ao transdisciplinar: a formação em Gestão Ambiental em discussão. Em aberto, Brasília, v. 27, n. 91, p. 59-69, 2014.

SINAES. Sistema Nacional de Avaliação da Educação Superior. Diretrizes para a avaliação das instituições de educação superior. Brasília, DF: MEC/Inep, 2004.

SOUZA, Maria Luisa H. Avaliação da efetividade dos principais cursos FIC Pronatec do Instituto Federal de Santa Catarina: benchmarking com cursos técnicos de longa duração. 2016. 63 f. Dissertação (Mestrado em Políticas Públicas) - Universidade de Brasília, Brasília, DF, 2016.

TIMOSSI, Luciana da Silva; SANTOS Jr., Guataçara dos; FRANCISCO, Antônio Carlos de. Procedimento no planejamento de amostras em pesquisa sobre qualidade de vida. In: ENCONTRO NACIONAL DE ENGENHARIA DE PRODUÇÃO, 28., 2008, Rio de Janeiro. Anais... Rio de Janeiro: ENEGEP, 2008. p. 1 - 11.

UERN. Projeto pedagógico do curso de GAM da Universidade do Estado do Rio Grande do Norte (UERN). Mossoró, 2012. 
UFSCar. Universidade Federal de São Carlos. Relatório final: acompanhamento da carreira profissional dos ex-alunos e avaliação da UFSCar/Curso pelos egressos de graduação. São Carlos: UFSCar, 2014.

UNB. Universidade de Brasília. Faculdade UnB Planaltina. Bibliotecas setoriais. Brasília, DF: UnB, s/d. Disponível em: <http://www.bce.unb.br/>. Acesso em: 28 abr. 2016.

UNB. Universidade de Brasília. Câmara de Ensino de Graduação. Ata da 1239a reunião da CEG. Brasília, DF: UnB, 2011a. Realizada em: 30 de agosto de 2011. Disponível em: <http://unb2.unb.br/administracao/ decanatos/deg/downloads/ceg/atas_ceg_2011/1239.pdf>. Acesso em: 22 fev. 2017.

UNB. Universidade de Brasília. Faculdade UnB Planaltina. Projeto político-pedagógico: bacharelado em gestão ambiental. Brasília, DF: UnB, 2011b.

UNB. Universidade de Brasília. Decanato de graduação da UnB. Taxa de sucesso FUP/Direção - DEG/SAA/ SIGRA. Brasília, DF: UnB, 2015. Disponível em: <http://www.unb.br/>. Acesso em: 20 maio 2016.

UNIVERSO EAD. Universidade Salgado de Oliveira. s/d. Disponível em: <http://online.universo.edu.br/ cursos/tecnologo/>. Acesso em: 28 abr. 2016.

Recebido em: 13.07.2016

Aprovado em: 21.03.2017

Alexandre Nascimento de Almeida é professor do curso de Gestão Ambiental, na área de Ciências Sociais Aplicadas, da Faculdade UnB de Planaltina (FUP). 